\title{
Fabrication of hydrophobic flat sheet and hollow fiber membranes from PVDF and PVDF-CTFE for membrane distillation
}

\author{
Jun Wang ${ }^{\mathrm{a}, \mathrm{b}, *}$, Libing Zheng ${ }^{\mathrm{a}, \mathrm{b}}$, Zhenjun $\mathrm{Wu}^{\mathrm{c}}$, Yong Zhang ${ }^{\mathrm{a}, \mathrm{b}}$, Xiaohui Zhang ${ }^{\mathrm{a}, \mathrm{b}}$ \\ ${ }^{a}$ Key Laboratory of Drinking Water Science and Technology, Research Center for Eco-Environmental Sciences, Chinese Academy of Sciences, Beijing 100085, \\ China \\ ${ }^{\mathrm{b}}$ Beijing Key Laboratory of Industrial Wastewater Treatment and Reuse, Research Center for Eco-Environmental Sciences, Chinese Academy of Sciences, \\ Beijing 100085, China \\ ${ }^{\mathrm{c}}$ College of Chemical Engineering and Environment, Beijing Institute of Technology, Beijing 100081, China
}

\section{A R T I C L E I N F O}

\section{Article history:}

Received 31 May 2015

Received in revised form 9 September 2015

Accepted 12 September 2015

Available online 16 September 2015

Keywords:

PVDF-CTFE copolymer

Hydrophobicity

Phase inversion

Pore structure and morphology

DCMD

\begin{abstract}
A B S T R A C T
Hydrophobic polyvinylidene fluoride (PVDF) membranes have been used in membrane distillation, however its performance in terms of permeation flux and salt rejection still needs to be improved. In this study, polyvinylidenedifluoride-co-chlorotrifluoroethylene (PVDF-CTFE), a PVDF based copolymer, was employed to fabricate both flat sheet and hollow fiber membranes. Two pore forming additives (PEG and $\mathrm{LiCl}$ ) were used in order to examine their effects on the membrane micro-structure and consequently the distillation performance. The crystalline property of the polymers was studied via X-ray diffraction (XRD) and Fourier transform infrared spectroscopy (FT-IR) to reveal its role in the membrane formation. The membrane morphology (SEM), surface property (AFM) and membrane properties (contact angle, pore size, porosity and pore size distribution) were systematically examined and compared among PVDF, PVDF-CTFE membranes as well as their counterparts with pore forming additives. The results revealed that PVDF-CTFE membrane exhibited optimal membrane morphology, pore structure and hydrophobicity, thus delivering better distillation performance (permeation flux up to $62.09 \mathrm{~kg} / \mathrm{m}^{2} \mathrm{~h}$, and distillate conductivity as low as $5 \mu \mathrm{S} / \mathrm{cm}$ ) in comparison with their PVDF membrane counterparts.
\end{abstract}

(c) 2015 Elsevier B.V. All rights reserved.

\section{Introduction}

Fluoro-polymers have a wide range of applications in membrane science owing to their excellent mechanical strength, superior chemical and thermal stability and low surface tension [1]. Among the entire fluoro-polymer family, polyvinylidene fluoride (PVDF) is the most commonly used membrane material for a variety of applications including microfiltration (MF), ultrafiltration (UF), nanofiltration (NF), membrane distillation (MD), pervaporation (PV) and gas separation (GS) [2,3]. The use of PVDF membrane in MD is particularly common due to its hydrophobicity and its excellent processability in comparison with other typically used polymer materials such as polypropylene (PP) and polytetrafluoroethylene (PTFE).

The research of PVDF hydrophobic membrane has mainly focused on the production of well-structured, super-hydrophobic membranes with good mechanical strength. The membrane with

\footnotetext{
* Corresponding author at: Key Laboratory of Drinking Water Science and Technology, Research Center for Eco-Environmental Sciences, Chinese Academy of Sciences, 18 Shuangqing Road, Haidian District, Beijing 100085, China. Fax: +8610 62917202.

E-mail address: junwang@rcees.ac.cn (J. Wang).
}

such ideal properties can be prepared through (i) careful selection of dope solution components and (ii) optimization of the membrane fabrication protocols. In this line of development, through a comprehensive study on dope solution compositions, hydrophobic PVDF flat-sheet membranes with permeation flux of $9.7 \mathrm{~kg} / \mathrm{m}^{2} \mathrm{~h}$ was prepared by Tomaszewska et al. for MD process [4]. Bottino et al.[5] further carried out a systematic study on the choice of appropriate organic solvents for PVDF membrane preparation, and more works have been done with the consideration of solvents effect on membrane morphology, hydrophobicity, micro-structure and separation performance [6]. In addition, research efforts had been made to the optimization of the preparation conditions, especially for hollow fiber membrane spinning. The parameters including the type and temperature of the coagulation, air gap distance, dope and bore liquid flow rates, take-up speed and posttreatment conditions had been investigated.

Apart from the aforementioned investigations, improving PVDF membrane performance from material development aspect has become another research focal point [7]. The research efforts on this front have mainly focused on three approaches: (i) the potential use of a variety of additives or mixed-solvent in the dope solution [8-10], (ii) development of smart membrane architecture, for instance, composite and nano-composite membranes [11-14] 
Table 1

Preparation parameters and casting conditions of flat-sheet membrane.

\begin{tabular}{|c|c|c|c|c|}
\hline Preparation conditions/parameters & M1 & M2 & M3 & M4 \\
\hline Polymer concentration & PVDF-CTFE, 12 wt\% & PVDF, 12 wt\% & PVDF-CTFE, 12 wt\% & PVDF, 12 wt\% \\
\hline Solvent concentration & DMAc, 88 wt $\%$ & DMAc, $88 \mathrm{wt} \%$ & DMAc, $80 \mathrm{wt} \%$ & DMAc, 80 wt $\%$ \\
\hline Additives (LiCl:PEG) & None & None & $8 w t \%(1: 1)$ & $8 \mathrm{wt} \%(1: 1)$ \\
\hline Coagulation & Deionized water & Deionized water & Deionized water & Deionized water \\
\hline Casting solution temperature $\left({ }^{\circ} \mathrm{C}\right)$ & 30 & 30 & 30 & 30 \\
\hline Coagulation temperature $\left({ }^{\circ} \mathrm{C}\right)$ & 30 & 30 & 30 & 30 \\
\hline Casting knife gap $(\mu \mathrm{m})$ & 250 & 250 & 250 & 250 \\
\hline Exposure time (s) & 15 & 15 & 15 & 15 \\
\hline
\end{tabular}

and (iii) synthesizing novel PVDF-based copolymer with enhanced properties [2]. In terms of the 3rd strategies of PVDF-based copolymer synthesis, one example is the synthesis of PVDF-TFE, which showed better mechanical and hydrophobic properties over PVDF membrane and has better performance in DCMD configuration [15]. More recently, PVDF-TFE novel polymer inclusion membranes (PIMs) were successfully prepared for $\mathrm{Cr}$ (VI) transport with high permeability and better selectivity [16]. In addition, another type of PDVF copolymer, PVDF-TrFE was used to prepare membranes for lithium-ion battery [17]. PVDF-HFP, as another commonly used PVDF-based copolymer, has also been widely investigated, not only on the optimization of the membrane preparation protocols [18-20], but also on its potential applications from ethyl acetate separation [21] to lithium-ion batteries [22,23].

PVDF-CTFE is another common PVDF-based copolymer, similar to PVDF-HFP, it has high mechanical strength and good chemical and thermal stability [24]. Furthermore, owing to its CTFE segment, PVDF-CTFE can be easily grafted via atom transfer radical polymerization (ATRP) without compromising the mechanical, thermal and chemical stability. For instance, Kim et al. [25] synthesized graft copolymer PVDF-CTFE-g-PSSA by ATRP and applied it as electrolyte membranes. Later they prepared PVDF-CTFE-gPSSA composite NF membrane [26]. In addition, poly(hydroxyl ethyl acrylate) [27], 4-vinylpyridine [28], and poly (oxyethylene methacrylate) [29] have been grafted onto the PVDF-CTFE main chains to obtain the corresponding amphilic copolymer membranes for either proton conducting properties or silver nanoparticle templates. In 2011, Liu et al. [30] prepared PVDF-CTFE hydrophobic membranes followed by the hydrophilic modification with immobilization of hydrophilic poly(ethylene glycol) methyl ether methacrylate (PEGMA) by ATRP.

However despite the great research efforts paid on the PVDFbased copolymer development, especially the PVDF-CTFE-based grafted polymers, all the attentions have been dedicated to enhancing the hydrophilicity of the membranes, whilst their potential in hydrophobic membrane preparation has been largely overlooked. Although the investigations on the use of PVDF membrane for MD process has been carried out in the past as aforementioned, the use of PVDF-based copolymer, PVDF-CTFE in particular, in the same MD application has never been explored, and the performance comparison between the conventional PVDF and PVDF-CTFE membranes was also not evaluated in the past, to the best knowledge of the authors. In this regard, the research in this line is certainly necessary and warranted.

Here, we report on the preparation of PVDF-CTFE and PVDF hydrophobic flat-sheet and hollow fiber membranes through the non-solvent induced phase separation technique (NIPS). The effect of the pore forming additives (PEG and $\mathrm{LiCl}$ ) was also assessed. The membrane morphology (SEM), surface property (AFM) and membrane properties (contact angle, pore size, porosity and pore size distribution) were systematically examined and compared among PVDF, PVDF-CTFE membranes as well as their counterparts with pore forming additives. The performance of these membranes in membrane distillation process was also studied to demonstrate its potential in industrial implementation.

\section{Experimental}

\subsection{Materials}

Commercial PVDF-CTFE copolymer (Solef ${ }^{18}$ PVDF 32008) and PVDF homopolymer (Solef ${ }^{18}$ PVDF 1015) were purchased from Solvay (Belgium) and was dried at $50{ }^{\circ} \mathrm{C}$ for $24 \mathrm{~h}$ before use. DMAC ( $>99 \%$ ) was employed as the solvent, which was obtained from Shanghai Jingwei Chemical Co., Ltd. (Shanghai, China). LiCl and polyethylene glycol (PEG) were used as the additives, both $\mathrm{LiCl}$ (AR, > 95\%) and PEG-400 (AR, > 99.5\%) were supplied by Tianjin Guangfu Research Institute of Fine Chemical Engineering (Tianjin, China). Ethanol (GR grade, 99.9\%), $\mathrm{NaCl}$ (GR grade, 99.5\%), glycerol (AR, 99\%), and diiodomethane (CP) were purchased from Beijing Chemical works (Beijing, China). In terms of the flat sheet membrane casting, deionized water was used as coagulant. Whilst for the hollow fiber fabrication, deionized water was used as bore solution, and tap water as external coagulant. All reagents and materials were used as received.

\subsection{Membrane preparation}

The PVDF-CTFE and PVDF polymers were dried at $50{ }^{\circ} \mathrm{C}$ for $24 \mathrm{~h}$ prior to polymer solution preparation. Different amounts of polymers, solvents and non-solvent additives were mixed in a sealed flask and stirred at $30^{\circ} \mathrm{C}$ for $24 \mathrm{~h}$ to obtain a homogeneous polymer solution (detailed polymer solution compositions can be found in Tables 1 and 2). The polymer solution was then allowed for degassing in an oven at $30^{\circ} \mathrm{C}$ for $24 \mathrm{~h}$.

Dry-wet phase inversion process was adopted to prepare the flat sheet membrane. A piece of hydrophilic PET nonwoven fabric $(18 \mathrm{~cm} \times 20 \mathrm{~cm})$ was firstly attached on a glass plate, followed by the casting of the polymer solution on the nonwoven fabric with a $0.25 \mathrm{~mm}$ casting knife. After exposing in the air for $15 \mathrm{~s}$, the film was immersed in a deionized water bath at $25^{\circ} \mathrm{C}$ to allow for the phase inversion. The nascent flat sheet membrane was then collected from the water bath and rinsed with deionized water to remove the residual solvent and non-solvent additives. Finally, the wet flat sheet membrane was dried in air at room temperature. The polymer solution compositions along with the casting conditions are compiled in Table 1.

In this study, asymmetric PVDF and PVDF-CTFE hollow fiber membranes were also fabricated utilizing the dry-jet wet spinning technique. The dope solution was extruded through a spinneret with a gear pump to control the dope flow rate. The nascent hollow fiber membrane went through an air gap before immersing into the coagulation bath, before being collected by a roller with a fixed take-up speed. The hollow fibers were then stored in a tap water bath for at least 2 days to remove the residual solvent and 
Table 2

Preparation parameters and spinning conditions of hollow fiber membrane.

\begin{tabular}{lll}
\hline $\begin{array}{l}\text { Preparation parameters/spinning } \\
\text { conditions }\end{array}$ & M5 & M6 \\
\hline Polymer concentration & PVDF-CTFE, 12 wt\% & PVDF, 12 wt\% \\
Solvent concentration & DMAc, 80 wt\% & DMAc, 80 wt\% \\
Additives (LiCl:PEG) & 8 wt\% (1:1) & 8 wt\% (1:1) \\
Dope solution flow rate $(\mathrm{L} / \mathrm{h})$ & 1.2 & 1.2 \\
Bore solution flow rate $(\mathrm{L} / \mathrm{h})$ & 0.5 & 0.5 \\
Bore solution & Deionized water & Deionized water \\
External coagulation & Tap water & Tap water \\
Casting solution temperature $\left({ }^{\circ} \mathrm{C}\right)$ & 30 & 30 \\
Coagulation temperature $\left({ }^{\circ} \mathrm{C}\right)$ & 30 & 30 \\
Spinneret OD/ID $(\mathrm{mm} / \mathrm{mm})$ & $1.8 / 1.2$ & $1.8 / 1.2$ \\
Air gap distance $(\mathrm{cm})$ & 10 & 10 \\
Take-up speed $(\mathrm{m} / \mathrm{s})$ & 0.35 & 0.35 \\
\hline
\end{tabular}

additives, prior to the final drying step in air at room temperature. The detailed hollow fiber spinning conditions are listed in Table 2.

\subsection{Polymer and membrane characterization}

The polymer chemistries were evaluated using a Nicolet iS10 FTIR spectrometer (Thermo Scientific, USA). All spectra were recorded in a wave number range of $4000-400 \mathrm{~cm}^{-1}$ by cumulating 64 scans at a resolution of $2 \mathrm{~cm}^{-1}$. The crystallinity of the polymers and their structural changes were investigated by XRD measurement using an X'Pert PRO MPD XRD instrument (PANalytical, The Netherlands). Data were collected from $10^{\circ}$ to $90^{\circ}$ at rate of $5 \% \mathrm{~min}$.

The ternary phase diagram of a polymer/solvent/non-solvent system was constructed using the cloud-point titration method. Specific amounts of polymer range from $2 \mathrm{wt} \%$ to $20 \mathrm{wt} \%$ for both PVDF-CTFE and PVDF were firstly dissolved in DMAc solvent and stirred $30{ }^{\circ} \mathrm{C}$ until a homogeneous solution was obtained. Deionized water (non-solvent) was slowly titrated into the polymer solution, with a magnetic stirrer vigorously mixing the solution. The titration process stopped when the solution became turbid or showed signs of gelation, and re-started when the solution became homogeneous again. This process was repeated until the solution became permanently turbid, and the composition of each component at this so-called titration end-point was calculated and mapped on the ternary phase diagram. Then the same procedure was repeated with other polymer concentrations and a series of titration end-points was mapped on the ternary phase diagram to form the binodal curve. The detailed composition of the casting solutions for titration and the titrimetric amount of $\mathrm{H}_{2} \mathrm{O}$ for each solution were listed in Table 3.

The membrane surface and cross-section morphologies were

Table 3

Composition of PVDF and PVDF-CTFE solutions at cloud points.

\begin{tabular}{lllll}
\hline Solutions code & PVDF $(\mathrm{g})$ & PVDF-CTFE $(\mathrm{g})$ & DMAc $(\mathrm{g})$ & $\mathrm{H}_{2} \mathrm{O}(\mathrm{g})$ \\
\hline $\mathrm{P} 1 / \mathrm{C} 1$ & $2 / 0$ & $0 / 2$ & $98 / 98$ & $12.7 / 15.8$ \\
$\mathrm{P} 2 / \mathrm{C} 2$ & $4 / 0$ & $0 / 4$ & $96 / 96$ & $10.3 / 13.6$ \\
$\mathrm{P} 3 / \mathrm{C} 3$ & $6 / 0$ & $0 / 6$ & $94 / 94$ & $8.6 / 11.3$ \\
$\mathrm{P} 4 / \mathrm{C} 4$ & $8 / 0$ & $0 / 8$ & $92 / 92$ & $7.8 / 10.2$ \\
P5/C5 & $10 / 0$ & $0 / 10$ & $90 / 90$ & $6.4 / 8.6$ \\
P6/C6 & $12 / 0$ & $0 / 12$ & $88 / 88$ & $5.6 / 6.9$ \\
P7/C7 & $15 / 0$ & $0 / 15$ & $85 / 85$ & $4.2 / 5.2$ \\
P8/C8 & $18 / 0$ & $0 / 18$ & $82 / 82$ & $3.9 / 4.3$ \\
P9/C9 & $20 / 0$ & $0 / 20$ & $80 / 80$ & $2.6 / 3.4$ \\
\hline
\end{tabular}

(Note: $\mathrm{P}$ and $\mathrm{C}$ represent the solution of PVDF and PVDF-CTFE, respectively. The contents before "/" were the composition of PVDF solution, and the contents after " " were the composition of PVDF-CTFE solution. The content of $\mathrm{H}_{2} \mathrm{O}$ was the titrimetric amounts of non-solvent as cloud point was achieved). studied through examining the SEM images using a HITACHI SU8020 field emission scanning electron microscope (FE-SEM) (Hitachi, Japan). The membrane samples were prepared through cryogenic fracturing followed by gold coating under vacuum using a HITACHI E-1010 Ion Sputtering device (Hitachi, Japan).

The surface properties of flat sheet membrane were also evaluated using an atomic force microscope (AFM) SPM-9600 (Shimadzu, Japan). The 3-D surface morphology and depth distribution of the membrane surface were obtained and the surface roughness was then calculated by the attached software.

The membrane contact angle was assessed using deionized water, glycerol and diiodomethane with OCA 15EC Video-Based Contact Angle Meter (Data Physics, Germany), and 5 places was measured for each membrane. The surface free energy was then calculated according to the Owens method [31]:

$\gamma_{L}(1+\cos \theta)=2\left(\gamma_{S}^{d} \gamma_{L}^{d}\right)^{1 / 2}+2\left(\gamma_{S}^{p} \gamma_{L}^{p}\right)^{1 / 2}$

where $\gamma_{S}$ and $\gamma_{L}$ are the surface energy of the solid and liquid respectively, $\gamma_{S}^{d}, \gamma_{S}^{p}, \gamma_{L}^{d}, \gamma_{L}^{p}$ are the dispersion force and polar force of the solid and the liquid respectively. The surface energy of the liquids used in this study and their dispersion force and polar force are presented in Table 4.

The overall porosity was determined by measuring the weight of the liquid contained in the membrane pores. A $4 \times 4 \mathrm{~cm}^{2}$ membrane sample was tore apart off from the nonwoven fabric and immersed in ethanol (a low surface energy liquid) for $24 \mathrm{~h}$, followed by another $24 \mathrm{~h}$ in deionized water. The weight of the wet membrane samples were weighed and then placed in an oven at $60{ }^{\circ} \mathrm{C}$ for $24 \mathrm{~h}$. The dried membranes were then weighed. The membrane porosity $(\varepsilon)$ was calculated by the following equation:

$\varepsilon=\frac{\left(M_{\mathrm{w}}-M_{d}\right) / \rho_{w}}{\left(M_{\mathrm{w}}-M_{d}\right) / \rho_{w}+M_{d} / \rho_{p}}$

where $M_{\mathrm{w}}$ is the weight of the wet membrane, $M_{\mathrm{d}}$ is the weight of the dry membrane, $\rho_{\mathrm{w}}$ and $\rho_{\mathrm{p}}$ are the density of water and membrane, respectively. Each membrane was measured for 3 times with different coupon prepared by the same solution under the same condition.

The bubble point and pore size distribution of the flat sheet membranes were investigated using a Capillary Flow Porometer Porolux 1000 (Porolux, Belgium) by gas permeation method. The membrane samples were firstly completely wetted with Porefil ${ }^{\text {in }}$ (Porolux, Belgium), the surface tension and density of which are $16 \mathrm{dyn} / \mathrm{cm}$ and $1.87 \mathrm{~g} / \mathrm{ml}$ respectively. Pure nitrogen was then allowed to flow into the sample chamber gradually. The bubble point was identified when the nitrogen pressure became higher than the capillary flow of the fluid within the largest pore. After determining the bubble point, the pressure was further increased and the nitrogen permeation rate was measured until all the pores were empty of Porefil ${ }^{\mathbb{R}}$, and the sample was considered dry. Nitrogen pressure and permeation flow rates through the dry sample were also recorded automatically by the software program after the wet curve was obtained. Based on the nitrogen flow rates through the wet and dry membranes, the pore size and pore size distribution were then calculated by the attached software.

Table 4

Surface property of the reagent.

\begin{tabular}{lcllll}
\hline Reagent & $\gamma_{L}^{p}$ & $\gamma_{L}^{d}$ & $\gamma_{L}$ & $\gamma_{L}^{p} / \gamma_{L}^{d}$ & Polarity \\
\hline Water & 51 & 21.8 & 72.8 & 2.36 & Polar \\
Glycerol & 26.4 & 37 & 63.4 & 0.71 & Polar \\
Diiodomethane & 2.3 & 48.5 & 50.8 & 0.05 & Non-polar \\
\hline
\end{tabular}




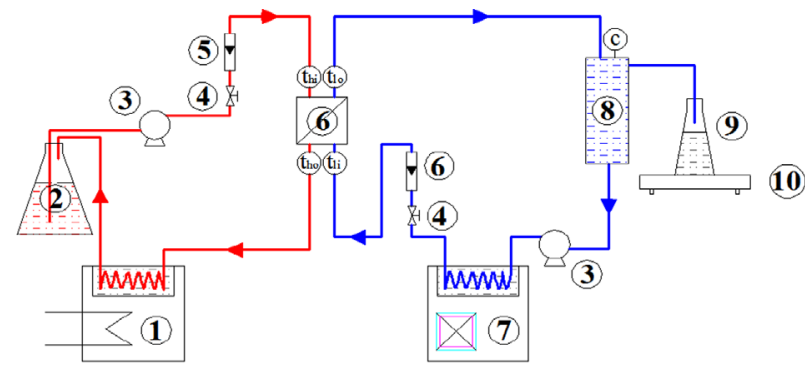

1. Super thermostat bath 2. Feed solution 3. Magnetic pump 4. Valve 5. Rotameter 6. Membrane module 7. Cryostat 8. Permeate 9. Conical flask 10. Balance t. Thermometer c. Conductivity meter

Fig. 1. Schematic diagram of the experimental DCMD set-up.

\subsection{Direct contact membrane distillation (DCMD)}

The performance of the in-house synthesized membranes was evaluated through a DCMD set-up. In terms of the flat sheet membrane, membrane with an effective area of $5.218 \times 10^{-3} \mathrm{~m}^{2}$ was tightly clamped between the feed and distillate chambers. Whilst for the hollow fiber membranes, each module contained 30 hollow fiber membranes (averagely, OD: $1.42 \mathrm{~mm}$, ID: $1.14 \mathrm{~mm}$ ) housed inside a polyester tube (OD: $20 \mathrm{~mm}$, ID: $15 \mathrm{~mm}$ ) and sealed with epoxy resin. The effective membrane length was $100 \mathrm{~mm}$, with an effective area of $1.074 \times 10^{-2} \mathrm{~m}^{2}$.

The schematic representation of the DCMD set-up is shown in Fig. 1 which was similar to our previous work [32], while the membrane module in this study can be flat-sheet or hollow fiber module. A super thermostat bath (SC-1010, Nanjing Xinchen biotechnology, China) and a cryostat (DL-1015, Nanjing Xinchen biotechnology, China) were used to control and maintain test temperature of both side by heat exchange. Two magnetic pumps (MP215R, Shanghai Seisun Pumps, China) were used to circulate the hot feed (35 g/L aqueous sodium chloride solution) and the cold distillate in the membrane module, whilst the flow rates of hot feed and cold distillate were adjusted by two rotameters (LZS-15, Yuyao Yinhuan Flowmeter, China) and kept constant at $65 \mathrm{~L} / \mathrm{h}$ and $50 \mathrm{~L} / \mathrm{h}$. Co-current configuration was used in this work for both flat sheet and hollow fiber membrane modules, where the hot feed was entered from the upper side and the distillate enter from the bottom side as shown in Fig. 1. The temperatures were monitored at the inlet and outlet of the membrane module of feed and distillate sides. The concentration of $\mathrm{NaCl}$ in the distillate was monitored with an electric conductivity monitor (CM-230A, Shijiazhuang Create Instrumentation Technologies, China). The distillate flux $(J)$ was calculated by the following equation:

$J=\frac{m}{A \bullet t}$

where $J$ is the distillate flux $\left(\mathrm{kg} / \mathrm{m}^{2} \mathrm{~h}\right), m$ is the quantity of distillate $(\mathrm{kg}), A$ is the membrane effective area $\left(\mathrm{m}^{2}\right)$ and $t$ represents the sampling time (h). The rejection coefficient $R$ was calculated according to the following equation:

$R=\frac{C_{\mathrm{f}}-C_{\mathrm{p}}}{C_{\mathrm{f}}}$

where $C_{\mathrm{f}}$ and $C_{\mathrm{p}}$ are the salt concentrations of the feed and the distillate respectively. For membranes prepared by the same solution under the same condition, 3 membrane samples were chosen for DCMD test.

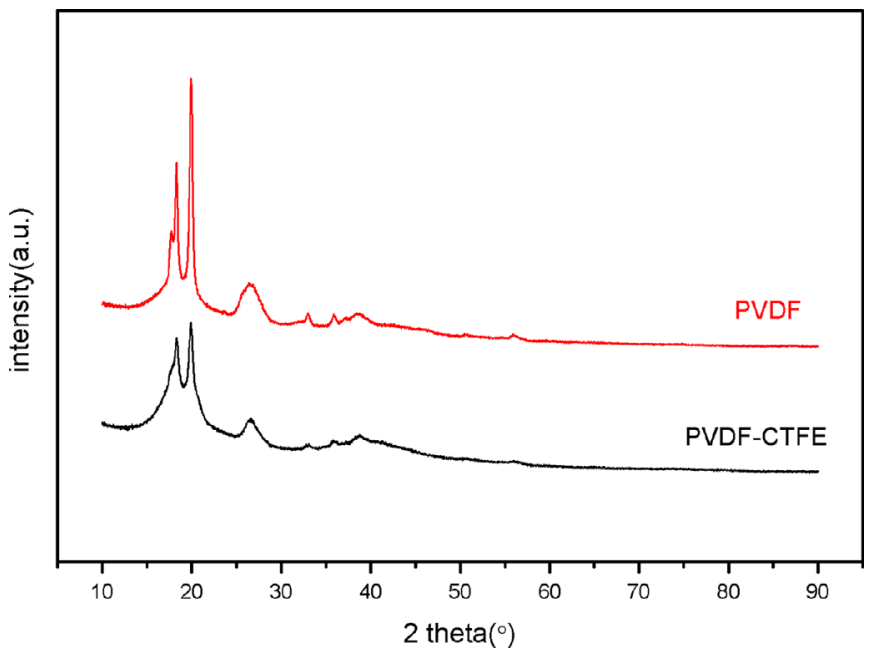

Fig. 2. XRD data of PVDF and PVDF-CTFE.

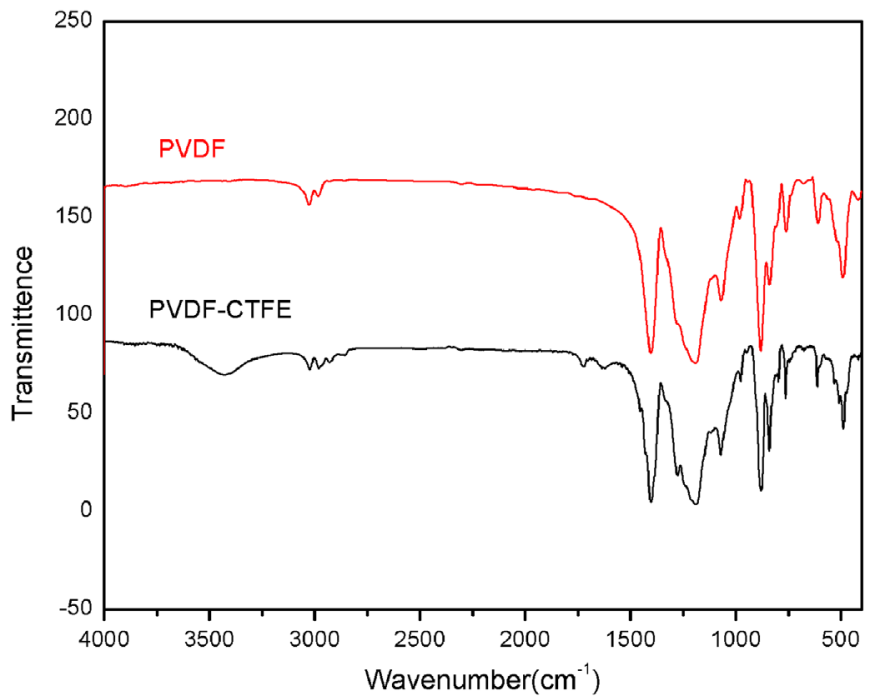

Fig. 3. FT-IR spectra of PVDF and PVDF-CTFE.

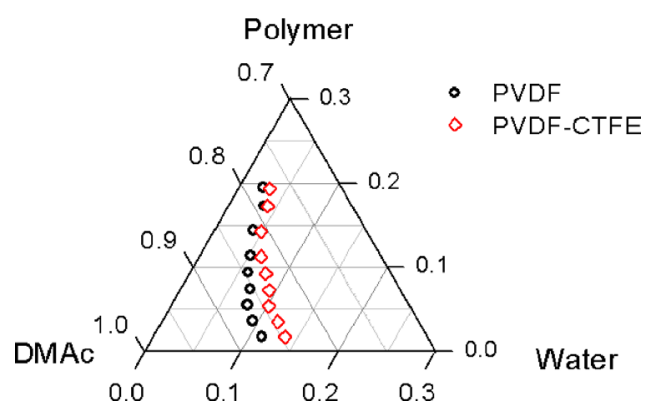

Fig. 4. Ternary phase diagram of PVDF and PVDF-CTFE with DMAc as solvent and water as non-solvent.

\section{Results and discussion}

\subsection{Properties of PVDF and PVDF-CTFE polymers}

PVDF homopolymer is semi-crystalline containing $59.4 \mathrm{wt} \%$ fluorine and $3 \mathrm{wt} \%$ hydrogen. It normally has 5 crystal polymorphs named $\alpha, \beta, \gamma, \delta$, and $\varepsilon$ with a crystallinity ranging between 35 and $70 \%$, depending on the preparation and thermal history. The PVDF homopolymer and PVDF-CTFE copolymer used in this work were 

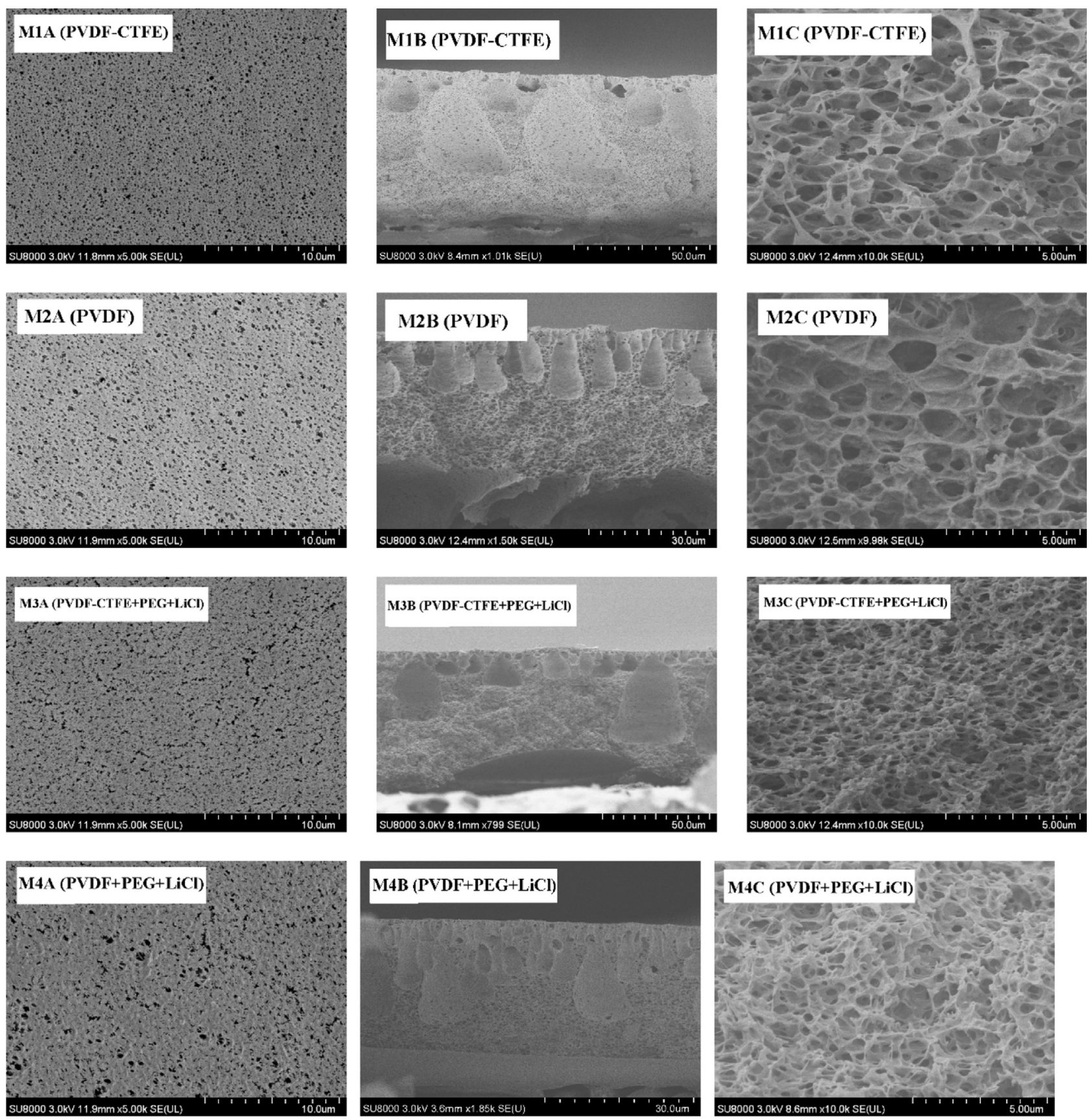

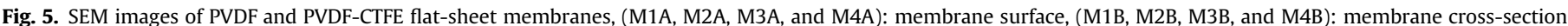
and (M1C, M2C, M3C and M4C): cross-section of the membrane sub-layer.

both purchased form Solvay, under the trademarks of Solef ${ }^{\mathrm{i}}$ PVDF 1015 and Solef ${ }^{\mathbb{E}}$ PVDF 32008, respectively. Solef ${ }^{16}$ PVDF 32008 is a copolymer of VDF and CTFE with a molar ratio of VDF:CTFE around 88:12 [33], which suggests that this PVDF copolymer may have a monoclinic crystalline structure [2].

The XRD results of PVDF and PVDF-CTFE polymers are presented in Fig. 2, typical semi-crystalline graphic peak appeared in both curves indicating the semi-crystal nature of these two polymers. PVDF showed peaks centered at diffraction angles of 17.72, $18.32,19.98$ and $26.75^{\circ}$ which suggested that the $\alpha$-phase crystal polymorph was dominated, although both $\alpha$-phase and $\beta$-phase peak appeared, while PVDF-CTFE showed peaks centered at diffraction angles of $18.32,19.95$ and $26.46^{\circ}$. The two XRD curves also suggested the convolution of amorphous and crystalline regions; the sharp crystalline peaks appeared due to the pseudo-hexagonal packing of helical chains with varying degrees of lateral and chain axis disorder. PVDF-CTFE curve showed similar peak position as PVDF with a slight peak shifting which may be caused by the incorporation of CTFE segment in VDF main chain. The curves also indicated that PVDF-CTFE has lower crystallinity degree compared to PVDF, evidenced by the higher peak for PVDF, as well as the narrower half peak width. The calculated crystallinity degree of PVDF and PVDF-CTFE were $57.13 \%$ and $37.70 \%$ respectively, which was in good agreement with the observation of the XRD curves.

The FT-IR spectra of PVDF and PVDF-CTFE are presented in Fig. 3. PVDF exhibited strong absorption band at around 3020, 2980, 1402, $1210,1180,1170,1070,976,840,796,763,614,510$ and $489 \mathrm{~cm}^{-1}$, where the peaks at 1210 and $1170 \mathrm{~cm}^{-1}$ were associated with $C F_{2}$ and peaks at $976,840,796,763,614$ and $510 \mathrm{~cm}^{-1}$ were due to the vibration of crystalline phase. As a comparison, PVDF-CTFE showed 

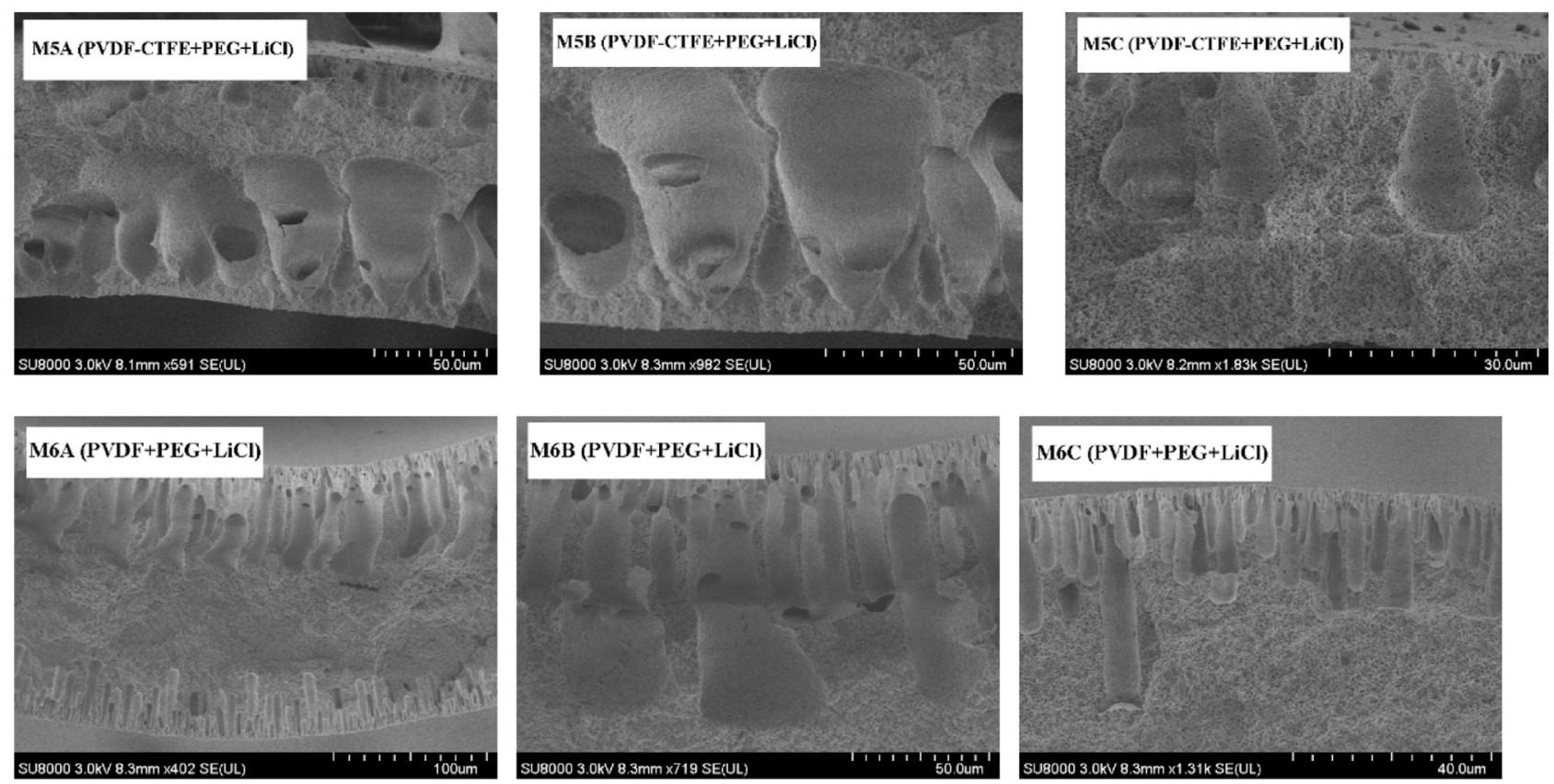

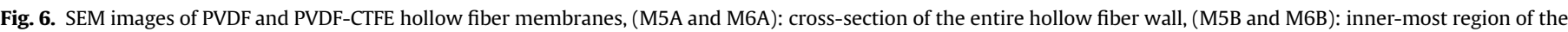
cross-section and (M5C and M6C): outer-most region of the cross-section.

almost identical peak positions with PVDF due to the same composition in the main chain. However, peak shifting and new peaks appeared in PVDF-CTFE spectra which can be ascribed to the incorporation of CTFE segment. The weak peak at $1272 \mathrm{~cm}^{-1}$ can be assigned to the vibration of C-F bond in CTFE, the peaks at $595 \mathrm{~cm}^{-1}$ and $976 \mathrm{~cm}^{-1}$ were the absorption peaks of $\mathrm{C}-\mathrm{Cl}$ bond.

\subsection{Phase diagram of polymer/DMAc/water ternary system}

The ternary phase diagram of polymer/DMAc/water system obtained by the cloud-point titration measurement (Table 3 ) is shown in Fig. 4. It was found that the binodal curve of PVDF-CTFE was located to the right of the binodal curve of PVDF, suggesting that the PVDF-CTFE solution was more stable, that is, larger amount of non-solvent will be required for PVDF-CTFE to induce phase inversion. Such an observation might be attributed to the different interaction strength among the polymer, solvent and non-solvent. In PVDF-CTFE solution, the exchange of solvent and non-solvent was slower during the phase inversion. This may affect the membrane formation process and the final membrane morphology.

It should be noted that the phase inversion behavior of the crystalline polymer was much more complex than that of the amorphous polymer due to the crystallization induced solid-liquid demixing, especially with higher polymer concentration [34-36]. It is clearly found that the end points of the titration process differed remarkably between low-concentration and high-concentration polymer solutions for both PVDF and PVDF-CTFE. When the polymer concentration was low, such as lower than $15 \mathrm{wt} \%$ for PVDF or lower than $12 \mathrm{wt} \%$ for PVDF-CTFE, the end points represented by the appearance of white solid. While the polymer was higher, the solution turned to translucent gel which indicated the crystallization of polymer represent the titration end. Yeow et al. [37] also found this phenomenon when they study the phase inversion behavior of PVDF/DMAc/additives/water systems. They inferred that the solvent-solute effect dominates the solution behavior in low-concentration solution, while the interaction between macromolecule was negligible. However, the interaction between macromolecules starts to interfere when polymer concentration was high. In the case of PVDF-CTFE, the casting solution was more stable and the solid-liquid demixing might have taken place earlier over PVDF, which indicated that PVDFCTFE copolymer was more likely to crystallization, as evidenced by the observation of the membrane micro-structure (SEM and AFM images provided in the following section).

\subsection{Membrane morphology}

The SEM images of the surface and the cross sections of the entire flat sheet membrane as well as the membrane sub-layer are presented in Fig. 5. It was found that all the flat sheet membrane displayed a typical morphology as the polymeric membranes formed through the liquid-liquid demixing, which contains a thin top layer, a sponge-like support layer with a number of finger-like macro-voids. More specifically, it can be seen that more finger-like macro-voids were present in PVDF membranes than PVDF-CTFE membrane. The formation of such a structure was mainly due to the instability of the PVDF polymer solution, as evidenced in Fig. 4, where the binodal curve of PVDF was located to the far left, meaning the instantaneous liquid-liquid demixing could take place for PVDF membrane, resulting in a quick formation of the skin layer which traps the solvent within the polymer matrix, consequently forms the finger-like macro-voids. Apart from the macro-voids, the SEM images also revealed that the pores formed in the sub-layer of PVDF-CTFE membrane was better interconnected than that of the PVDF membrane. In terms of the effect of PEG and $\mathrm{LiCl}$ additives, it was found the addition of PEG and $\mathrm{LiCl}$ improved the pore interconnectivity for both PVDF and PVDF-CTFE membranes in comparison with their pure polymeric counterparts.

The SEM images of the PVDF and PVDF-CTFE hollow fiber membranes are presented in Fig. 6. Similarly, better pore interconnectivity was found in PDVF-CTFE hollow fibers than their PVDF counterparts. It was also noted that large tear-like voids were found in the inner wall of the PVDF-CTFE hollow fibers, whereas in PVDF hollow fibers, such a structure was absent and narrow finger-like macro-voids were found instead. Such a phenomenon indicated that the phase inversion behavior during the formation of hollow fiber membrane is much more complicated than that of flat sheet 

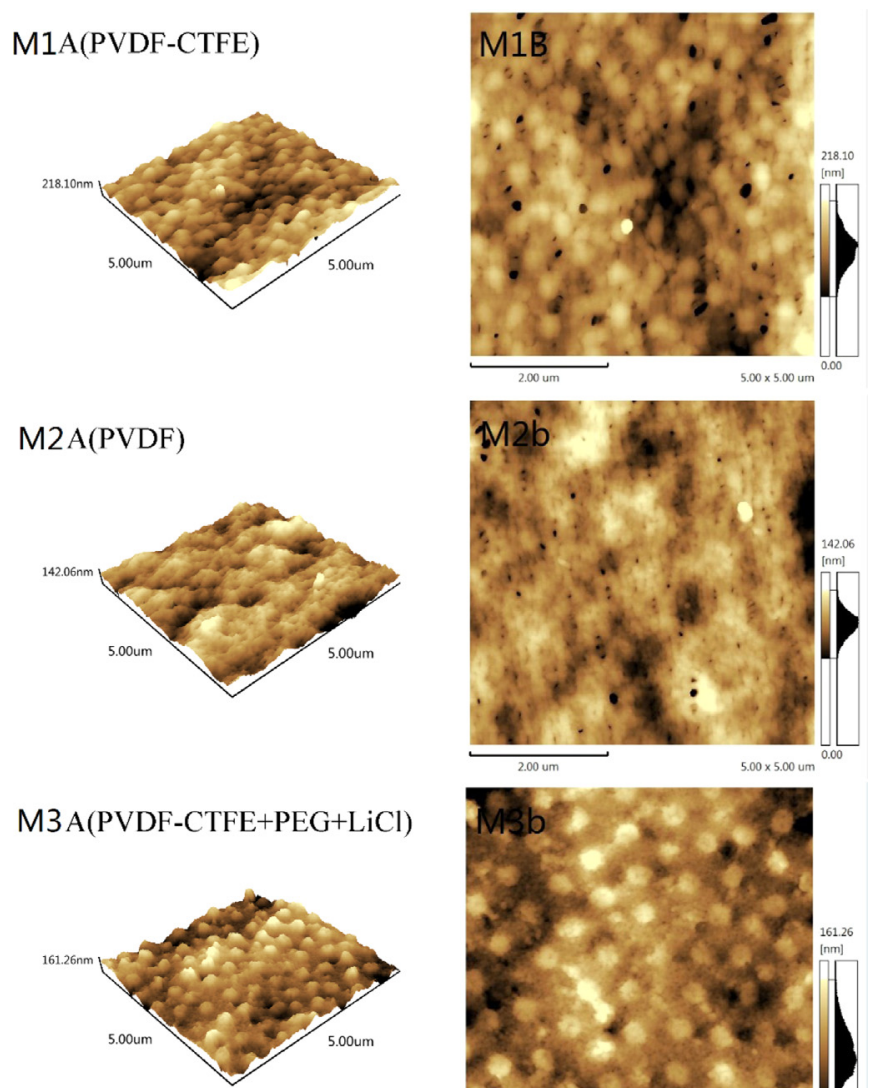

M4 A(PVDF+PEG+LiCl)

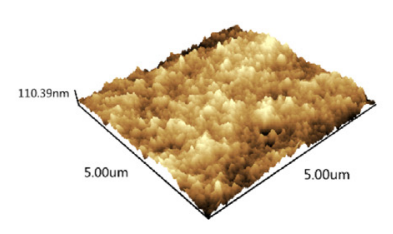

Table 7

Pore sizes and porosity of PVDF and PVDF-CTFE flat-sheet membranes.

\begin{tabular}{lllll}
\hline Membrane label & $\begin{array}{l}\text { Bubble } \\
\text { point pore } \\
\text { size }(\mu \mathrm{m})\end{array}$ & $\begin{array}{l}\text { Smallest } \\
\text { pore size } \\
(\mu \mathrm{m})\end{array}$ & $\begin{array}{l}\text { Mean } \\
\text { pore size } \\
(\mu \mathrm{m})\end{array}$ & Porosity (\%) \\
\hline M1 (PVDF-CTFE) & 0.1771 & 0.0663 & 0.0876 & $65.21 \pm 1.54$ \\
M2 (PVDF) & 0.1973 & 0.0674 & 0.0949 & $57.84 \pm 0.78$ \\
M3 (PVDF- & 0.2018 & 0.1070 & 0.1289 & $86.08 \pm 2.53$ \\
$\begin{array}{c}\text { CTFE + PEG + LiCl) } \\
\text { M4 (PVDF+PEG + LiCl) }\end{array}$ & 0.2368 & 0.1018 & 0.1315 & $74.62 \pm 2.84$ \\
\hline
\end{tabular}

membrane, and a systematical investigation is therefore essential to better understand the fundamentals of the hollow fiber membrane formation through phase inversion process.

\subsection{Membrane surface analysis}

The surface properties of a membrane have great influence on its hydrophilicity/hydrophobicity and its anti-fouling properties. In this study, the surface properties of PVDF and PVDF-CTFE flat sheet membranes were studied with AFM. As shown in Fig. 7, the PVDFCTFE flat sheet membranes showed coarser surface in comparison with their PVDF counterparts. As aforementioned, PVDF-CTFE copolymer was easier to crystallize in casting solution, clear spherical crystals were visible on the surface of PVDF-CTFE membranes, as seen in Fig. 7. In addition, it was also found that the addition of PEG and LiCl led to a smoother surface for both PVDF and PVDFCTFE membranes. Generally speaking, the phase inversion rate were improved as the addition of additives, and that was benefit for liquid-liquid demixing during membrane formation. That can be attributed to the suppression of crystallization and the formation of smoother surface.

The membrane roughness was calculated using the AFM analysis software as shown in Table 5. The average roughness $\left(R_{\mathrm{a}}\right)$ for the image is defined as the arithmetic average of the absolute values of the surface height deviations measured from the center plane, the root mean square roughness $\left(R_{\mathrm{q}}\right)$ represents the standard deviation from the mean surface plane, and the maximum roughness $\left(R_{\max }\right)$ is the vertical distance between the highest peaks and the lowest valleys in the image. The PVDF membrane with additives displayed the smoothest surface whilst pure PVDFCTFE membrane had the roughest surface. It indicated that the addition of additives can smooth the membranes surface morphology, which may be a reason for the decrease of membranes hydrophobicity as shown in Table 6 .

Fig. 7. AFM images of the PVDF and PVDF-CTFE flat-sheet membranes, (M1A, M2A, M3A and M4A): 3-D morphology of the membrane surface, and (M1B, M2B, M3B and M4B): depth distribution of the membrane surface.

Table 5

Surface roughness of PVDF and PVDF-CTFE flat-sheet membranes.

\begin{tabular}{|c|c|c|c|}
\hline Membrane label & $R_{\mathrm{a}}(\mathrm{nm})$ & $R_{\mathrm{q}}(\mathrm{nm})$ & $R_{\max }(\mathrm{nm})$ \\
\hline M1 (PVDF-CTFE) & 32.39 & 41.84 & 390.50 \\
\hline M2 (PVDF) & 21.13 & 27.38 & 360.11 \\
\hline M3 (PVDF-CTFE + PEG + $\mathrm{LiCl}$ ) & 24.47 & 30.65 & 216.01 \\
\hline $\mathrm{M} 4$ (PVDF+ $\mathrm{PEG}+\mathrm{LiCl})$ & 17.08 & 21.47 & 179.90 \\
\hline
\end{tabular}

Table 6

Contact angle $(C A)$ and surface energy $(\gamma)$ of PVDF and PVDF-CTFE flat-sheet membranes.

\begin{tabular}{|c|c|c|c|c|}
\hline Membrane label & $C A_{\text {water }}\left({ }^{\circ}\right)$ & $C A_{\text {glycerol }}\left({ }^{\circ}\right)$ & $C A_{\text {diiodomethane }}\left({ }^{\circ}\right)$ & $\gamma\left(\times 10^{-5} \mathrm{~N} \mathrm{~cm}^{-1}\right)$ \\
\hline M1 (PVDF-CTFE) & $105.3 \pm 3.4$ & $95.5 \pm 3.1$ & $69.6 \pm 2.4$ & 25.68 \\
\hline M2 (PVDF) & $98.4 \pm 5.1$ & $89.9 \pm 7.5$ & $66.3 \pm 1.7$ & 29.51 \\
\hline M3 (PVDF-CTFE + PEG + LiCl) & $98.7 \pm 6.7$ & $88.5 \pm 4.7$ & $60.8 \pm 3.6$ & 31.74 \\
\hline M4 (PVDF+ PEG + LiCl) & $91.4 \pm 3.6$ & $85.8 \pm 5.3$ & $57.3 \pm 2.3$ & 35.96 \\
\hline
\end{tabular}



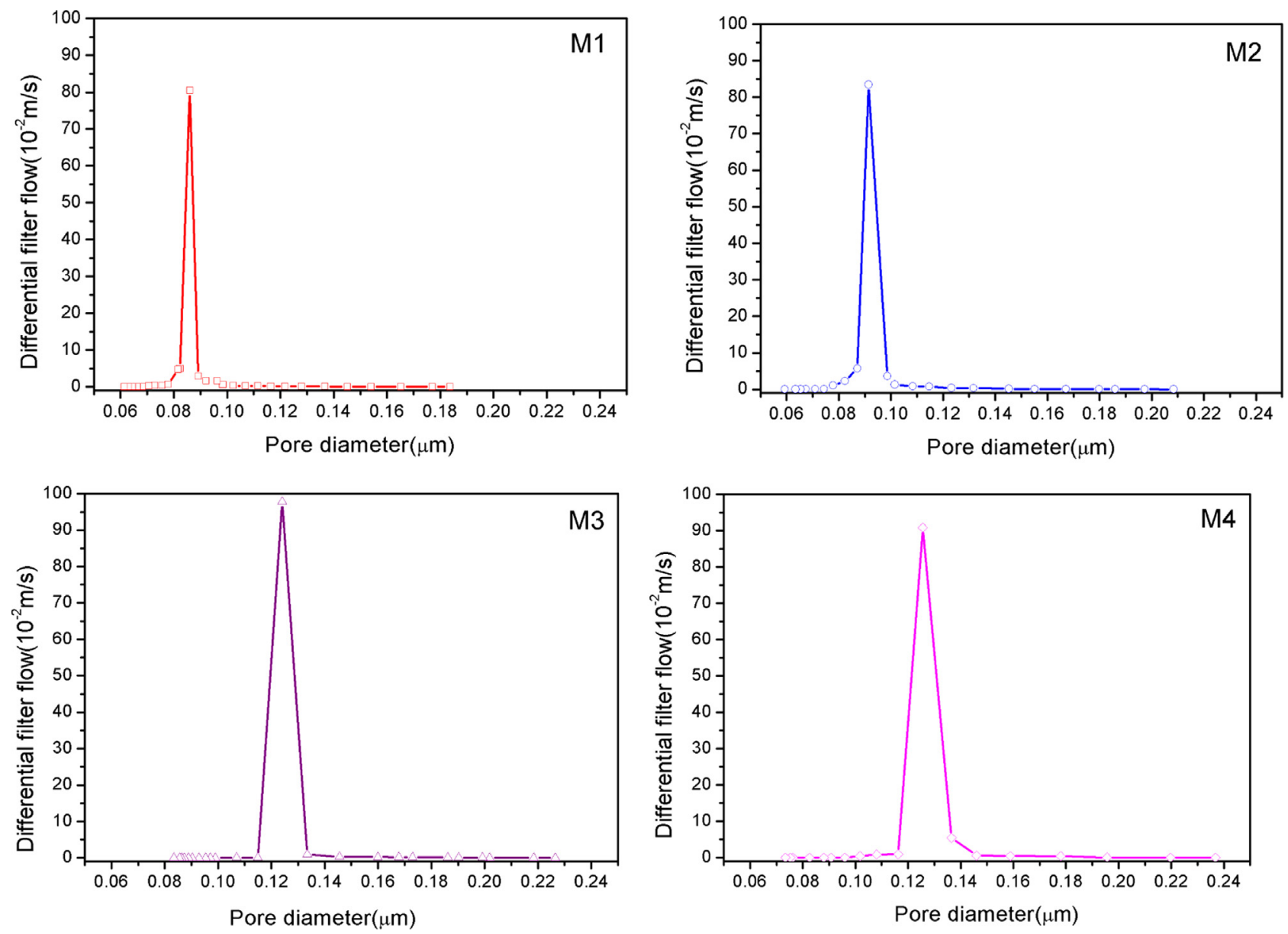

Fig. 8. Pore size distribution of PVDF and PVDF-CTFE flat-sheet membranes.

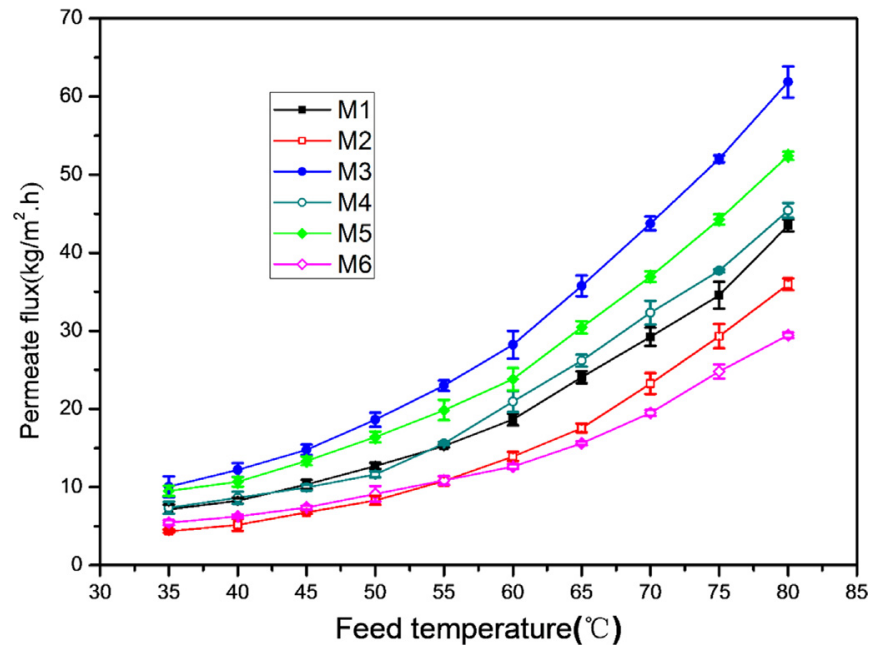

Fig. 9. Permeation flux profiles of all the flat-sheet and hollow fiber membranes as a function of feed temperature.

\subsection{Membrane contact angle and surface energy}

The contact angles of the PVDF and PVDF-CTFE flat sheet membranes were measured using water, glycerol and diiodomethane (Table 6). The PVDF-CTFE membrane showed higher contact angle thus more hydrophobic than the PVDF membrane. Furthermore, the addition of PEG and $\mathrm{LiCl}$ substantially lowered the contact angles of both PVDF and PVDF-CTFE flat sheet membranes. It indicated that the membranes became less hydrophobic due to the use of pore-

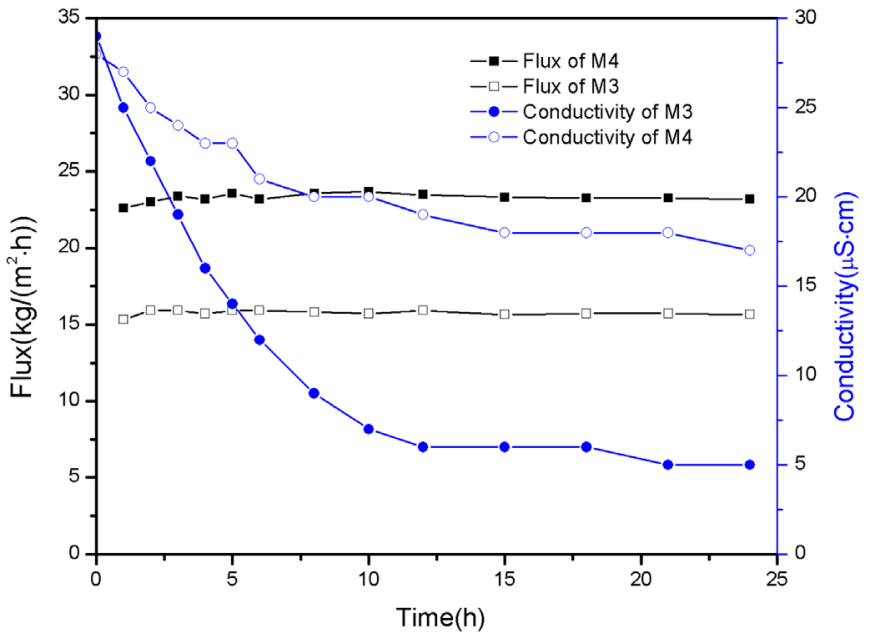

Fig. 10. Permeation flux and conductivity profiles of $\mathrm{M} 3$ (PVDF-CTFE $+\mathrm{PEG}+\mathrm{LiCl}$ ) and $\mathrm{M} 4(\mathrm{PVDF}+\mathrm{PEG}+\mathrm{LiCl})$ as a function of operating time.

forming additives, which was in accordance with AFM observation (Fig. 7) where the membrane roughness was decreased due to additives addition. The surface free energy was also calculated based on the contact angle measurements, and are shown in Table 6 . The free energy followed the order of: M1 (PVDF-CTFE) $<$ M2 $(\mathrm{PVDF})<\mathrm{M} 3 \quad(\mathrm{PVDF}-\mathrm{CTFE}+\mathrm{PEG}+\mathrm{LiCl})<\mathrm{M} 4 \quad(\mathrm{PVDF}+\mathrm{PEG}+\mathrm{LiCl})$, which was opposite of the trend seen from the membrane surface roughness as shown in Table 5: M1 (PVDF-CTFE) $>$ M2 (PVDF) $>$ M3 (PVDF-CTFE + PEG $+\mathrm{LiCl})>\mathrm{M} 4 \quad(\mathrm{PVDF}+\mathrm{PEG}+\mathrm{LiCl})$. Such an 
observation suggested that the membrane with higher surface roughness had lower surface energy thus more hydrophobic. For this point of view, the PVDF-CTFE appeared to be the candidate of choice for membrane distillation application due to its higher hydrophobicity.

\subsection{Porosity, pore size and pore distribution}

The porosity, the bubble point pore size, and the smallest pore size of the flat-sheet membrane were presented in Table 7. It was found that even though the PVDF-CTFE flat sheet membrane displayed smaller pore sizes than their PVDF membrane counterparts, the porosity of PVDF-CTFE membranes appeared to be larger, suggesting the better pore interconnectivity of the PVDF-CTFE membranes, which was evidenced by the SEM images shown in Fig. 5. Such a phenomenon can be ascribed to the different phase inversion process, especially the crystallization process that these membranes underwent during the membrane formation. In addition, the results presented in Table 7 clearly showed that the addition of PEG and LiCl substantially increased both the pore size and porosity of the membranes.

Fig. 8 presents the pore size distribution of all the flat-sheet membranes. It can be seen that the pore size distribution followed the order of M1 (PVDF-CTFE) $<$ M2 (PVDF) $<$ M3 (PVDF-CTFE + $\mathrm{PEG}+\mathrm{LiCl})<\mathrm{M} 4(\mathrm{PVDF}+\mathrm{PEG}+\mathrm{LiCl})$, which was identical with the order of the pore sizes. The PVDF-CTFE membrane (M1) had the narrowest pore size distribution. However, in terms of the differential filter flow rate which indicates the number of pores with determinative pore size, the PVDF-CTFE membrane with additives (M3) had the highest differential filter flow rate, suggesting that the addition of PEG and $\mathrm{LiCl}$ can the both suppression of the formation of large pores and small pores and obtain the narrower pore distribution.

\subsection{Membrane distillation performance}

The prepared flat-sheet and hollow fiber membranes were tested for DCMD process. During the experiment, the membrane module was vertically mounted to eliminate the effects of free convection and to remove air bubbles. The hot feed temperature at the inlet of membrane module, $\mathrm{Th}_{\mathrm{in}}$, was varied from $35^{\circ} \mathrm{C}$ to $80^{\circ} \mathrm{C}$, and the inlet temperature of the cold distillate, $\mathrm{Tc}_{\mathrm{in}}$, was maintained constant at $20^{\circ} \mathrm{C}$. The membrane permeation flux as a function of the hot feed temperature was shown in Fig. 9.

It was found that increasing the feed temperature led to the increase of the distillate fluxes for all the membranes due to the enhanced driving force. In general, the permeation fluxes followed the order of: $\mathrm{M} 3$ (PVDF-CTFE $+\mathrm{PEG}+\mathrm{LiCl})>\mathrm{M} 4$ (PVDF+PEG+ $\mathrm{LiCl})>\mathrm{M} 1$ (PVDF-CTFE) $>\mathrm{M} 2$ (PVDF), which was well corresponded to the order of porosity reported in Section 3.6. More specifically, the PVDF-CTFE membranes displayed higher permeation fluxes than their PVDF membrane counterparts despite of their relatively smaller pore size. Such a behavior suggested that the permeation flux was largely influenced by the pore interconnectivity, where a better interconnectivity contributed more to the enhanced permeation flux than a larger pore size, as evidenced in the SEM images (Fig. 5). Furthermore, the addition of PEG and $\mathrm{LiCl}$ significantly enhanced the permeation fluxes for both PVDFCTFE and PVDF membranes as shown in Fig. 9, demonstrating the pore forming functionality of these additives. In terms of the hollow fiber membranes (M5 and M6), similar trend of higher permeation fluxes in PVDF-CTFE hollow fiber membrane (M5) was found.

To investigate the performance sustainability, a $24 \mathrm{~h}$ continuous DCMD experiment of M3 (PVDF-CTFE + PEG + LiCl) and M4 $(\mathrm{PVDF}+\mathrm{PEG}+\mathrm{LiCl})$ was performed. The hot feed temperature at the inlet was fixed at $55^{\circ} \mathrm{C}$, whilst the cold distillate inlet temperature was set at $20^{\circ} \mathrm{C}$. The permeation flux and conductivity were continuously monitored throughout the entire course of the experiment, and the result are presented in Fig. 10. It should be noted that the distillate conductivity was decreased during the DCMD process from the initial deionized water which had the conductivity around $28 \mu \mathrm{S} / \mathrm{cm}$ to the final conductivity and maintained which can be view as the actual conductivity of the distillate. In terms of the permeation flux, both membranes exhibited stable permeation fluxes over the entire operating period, suggesting the absence of either membrane wetting or membrane fouling. In addition, the PVDF-CTFE membrane with additives (M3) displayed higher permeation flux than the PVDF-CTFE membrane (M4), which was in good agreement with the observation in Fig. 9. In the case of conductivity, it was observed that the final conductivity of M3 $(5 \mu \mathrm{S} / \mathrm{cm})$ was lower than that of M4 $(17 \mu \mathrm{S} / \mathrm{cm})$, the membrane hydrophobicity (Table 5 ) should be the reason for their salt rejection. These results demonstrated the good potential for PVDF-CTFE membrane to be used in membrane distillation process due to its excellent permeation properties and salt rejection.

\section{Conclusions}

In this study, a PVDF based copolymer, PVDF-CTFE, was employed to fabricate both flat sheet and hollow fiber membranes. Two pore forming additives (PEG and $\mathrm{LiCl}$ ) were used in order to examine their effects on the membrane micro-structure and consequently the distillation performance. The XRD and FT-IR results revealed PVDF-CTFE and PVDF have similar chemical structure with some different as the introduction of CTFE segment, which consequently influenced the membrane formation process, thus the membrane morphology. The PVDF-CTFE membrane displayed a unique micro-structure with high pore interconnectivity and narrow pore size distribution, which consequently resulted in the higher permeation flux when using such membranes in MD process in comparison with PVDF membrane. In addition, rougher membrane surface was observed via AFM for PVDF-CTFE membrane, which partially contributed to the higher hydrophobicity than PVDF membrane. As a result, higher salt rejection over 24 h MD operations was seen on PVDF-CTFE membrane, suggesting the absence of membrane wetting owing to the high hydrophobicity. Furthermore, the addition of pore forming agents (i.e. PEG and $\mathrm{LiCl}$ ) successfully increased the pore size and porosity of the membranes, which led to the higher permeation flux in the MD experiment. With the careful optimization of the fabrication conditions, the final PVDF-CTFE membrane offered exceptional distillation performance (permeation flux up to $62.09 \mathrm{~kg} / \mathrm{m}^{2} \mathrm{~h}$, and distillate conductivity as low as $5 \mu \mathrm{S} / \mathrm{cm}$ ) in comparison with PVDF membranes. These results demonstrated the great potential of using hydrophobic PVDF-CTFE membrane in the applications such as membrane distillation.

\section{Acknowledgments}

This work was supported by the National Water Pollution Control and Management Technology Major Project of China (No. 2012ZX07202006-003) and the National Natural Science Foundation of China (Grant no. 51378491 and 51578533). The authors would like to thank the editor and the anonymous reviewers for their editing and review. 


\section{List of Symbols}

PVDF Polyvinylidene fluoride

PVDF-CTFE Polyvinylidenedifluoride-cochlorotrifluoroethylene

PTFE Polytetrafluoroethylene

PEGMA Poly(ethylene glycol) methyl ether methacrylate

PVDF-TFE Poly(vinylidenefluoride-trifluoroethylene)

PVDF-HFP Poly(vinylidene fluoride-co-hexafluoropropylene)

PVDF-TrFE Poly(vinylidene fluoride-trifluoroethylene)

PEG Polyethylene glycol

PET Polyester

PE Polyethylene

PP Polypropylene

DMAc N, N-dimethylacetamide

NIPS Non-solvent induced phase separation technique

MF Microfiltration

UF Ultrafiltration

NF Nanofiltration

RO Reverse osmosis

MD Membrane distillation

DCMD Direct contact membrane distillation

PV Pervaporation

GS Gas separation

ATRP Atom transfer radical polymerization

ID Inside diameter

OD Outside diameter

$\gamma_{\mathrm{S}} \quad$ The surface energy of the solid

$\gamma_{\mathrm{L}} \quad$ The surface energy of the liquid

$\gamma_{S}^{d} \quad$ The dispersion force of the solid

$\gamma_{S}^{p} \quad$ The polar force of the solid

$\gamma_{L}^{d} \quad$ The dispersion force of the liquid

$\gamma_{L}^{p} \quad$ The polar force of the liquid

$\varepsilon \quad$ The membrane porosity

$M_{\mathrm{w}} \quad$ The weight of the wet membrane

$M_{\mathrm{d}} \quad$ The weight of the dry membrane

$\rho_{\mathrm{w}} \quad$ The density of water

$\rho_{\mathrm{p}} \quad$ The density of membrane

$J \quad$ The distillate flux

$M \quad$ The quantity of distillate

A Membrane effective area

$t \quad$ The sampling time

$R \quad$ The rejection coefficient

$C_{\mathrm{f}} \quad$ The salt concentrations of the feed

$C_{\mathrm{p}} \quad$ The salt concentrations of the distillate

$R_{\mathrm{a}} \quad$ The average roughness

$R_{\mathrm{q}} \quad$ The root mean square roughness

$R_{\max } \quad$ The maximum roughness

\section{References}

[1] B. Ameduri, From vinylidene fluoride (VDF) to the applications of VDF-containing polymers and copolymers: recent developments and future trends, Chem. Rev. 109 (2009) 6632-6686.

[2] Z. Cui, E. Drioli, Y.M. Lee, Recent progress in fluoropolymers for membranes, Prog. Polym. Sci. 39 (2014) 164-198.

[3] F. Liu, N.A. Hashim, Y. Liu, M. Abed, K. Li, Progress in the production and modification of PVDF membranes, J. Membr. Sci. 375 (2011) 1-27.

[4] M. Tomaszewska, Preparation and properties of flat-sheet membranes from poly (vinylidene fluoride) for membrane distillation, Desalination 104 (1996) $1-11$.

[5] A. Bottino, G. Capannelli, S. Munari, A. Turturro, Solubility parameters of poly (vinylidene fluoride), J. Polym. Sci. Part B: Polym. Phys. 26 (1988) 785-794.

[6] M.M. Tao, F. Liu, B.R. Ma, L.X. Xue, Effect of solvent power on PVDF membrane polymorphism during phase inversion, Desalination 316 (2013) 137-145.

[7] N.N. Li, A.G. Fane, W.W. Ho, T. Matsuura, Advanced membrane technology and applications, John Wiley \& Sons, New York, 2011.

[8] Q. Li, Z.L. Xu, L.Y. Yu, Effects of mixed solvents and PVDF types on performances of PVDF microporous membranes, J. Appl. Polym. Sci. 115 (2010) 2277-2287.

[9] Y.H. Zhao, B.K. Zhu, X.T. Ma, Y.Y. Xu, Porous membranes modified by hyperbranched polymers: I. Preparation and characterization of PVDF membrane using hyperbranched polyglycerol as additive, J. Membr. Sci. 290 (2007) 222-229.

[10] D. Wang, K. Li, W. Teo, Porous PVDF asymmetric hollow fiber membranes prepared with the use of small molecular additives, J. Membr. Sci. 178 (2000) $13-23$.

[11] N.A. Hashim, Y. Liu, K. Li, Preparation of PVDF hollow fiber membranes using $\mathrm{SiO}_{2}$ particles: the effect of acid and alkali treatment on the membrane performances, Indus. Eng. Chem. Res. 50 (2011) 3035-3040.

[12] D. Hou, J. Wang, X. Sun, Z. Ji, Z. Luan, Preparation and properties of PVDF composite hollow fiber membranes for desalination through direct contact membrane distillation, J. Membr. Sci. 405 (2012) 185-200.

[13] J. Prince, G. Singh, D. Rana, T. Matsuura, V. Anbharasi, T. Shanmugasundaram, Preparation and characterization of highly hydrophobic poly (vinylidene fluoride)-clay nanocomposite nanofiber membranes (PVDF-clay NNMs) for desalination using direct contact membrane distillation, J. Membr. Sci. 397 (2012) 80-86.

[14] C.L. Chang, M.S. Chang, Preparation of multi-layer silicone/PVDF composite membranes for pervaporation of ethanol aqueous solutions, J. Membr. Sci. 238 (2004) 117-122.

[15] C. Feng, B. Shi, G. Li, Y. Wu, Preparation and properties of microporous membrane from poly (vinylidene fluoride-co-tetrafluoroethylene)(F2. 4) for membrane distillation, J. Membr. Sci. 237 (2004) 15-24.

[16] L. Guo, Y. Liu, C. Zhang, J. Chen, Preparation of PVDF-based polymer inclusion membrane using ionic liquid plasticizer and Cyphos IL 104 carrier for Cr (VI) transport, J. Membr. Sci. 372 (2011) 314-321.

[17] C.M. Costa, A. California, V. Cardoso, V. Sencadas, L. Rodrigues, M. Silva, S. Lanceros-Méndez, Electroactive poly (vinylidene fluoride-trifluorethylene) (PVDF-TrFE) microporous membranes for lithium-ion battery applications, Ferroelectrics 430 (2012) 103-107.

[18] C. Feng, R. Wang, B. Shi, G. Li, Y. Wu, Factors affecting pore structure and performance of poly (vinylidene fluoride-co-hexafluoro propylene) asymmetric porous membrane, J. Membr. Sci. 277 (2006) 55-64.

[19] L. Shi, R. Wang, Y. Cao, C. Feng, D.T. Liang, J.H. Tay, Fabrication of poly (vinylidene fluoride-co-hexafluropropylene)(PVDF-HFP) asymmetric microporous hollow fiber membranes, J. Membr. Sci. 305 (2007) 215-225.

[20] L. Shi, R. Wang, Y. Cao, D.T. Liang. J.H. Tay, Effect of additives on the fabrication of poly (vinylidene fluoride-co-hexafluropropylene)(PVDF-HFP) asymmetric microporous hollow fiber membranes, J. Membr. Sci. 315 (2008) 195-204.

[21] X. Tian, X. Jiang, Poly (vinylidene fluoride-co-hexafluoropropene)(PVDF-HFP) membranes for ethyl acetate removal from water, J. Hazard. Mater. 153 (2008) $128-135$.

[22] W. Pu, X. He, L. Wang, C. Jiang, C. Wan, Preparation of PVDF-HFP microporous membrane for Li-ion batteries by phase inversion, J. Membr. Sci. 272 (2006) $11-14$.

[23] Z. Li, G. Su, X. Wang, D. Gao, P. Micro-porous, VDF-HFP)-based polymer electrolyte filled with $\mathrm{Al}_{2} \mathrm{O}_{3}$ nanoparticles, Solid State Ion. 176 (2005) 1903-1908.

[24] F. Boschet, B. Ameduri, (Co)polymers of chlorotrifluoroethylene: synthesis, properties, and applications, Chem. Rev. 114 (2013) 927-980.

[25] Y.W. Kim, J.K. Choi, J.T. Park, J.H. Kim, Proton conducting poly (vinylidene fluoride-co-chlorotrifluoroethylene) graft copolymer electrolyte membranes, J. Membr. Sci. 313 (2008) 315-322.

[26] J.H. Koh, Y.W. Kim, J.T. Park, B.R. Min, J.H. Kim, Nanofiltration membranes based on poly (vinylidene fluoride-co-chlorotrifluoroethylene)-graft-poly (styrene sulfonic acid), Polym. Adv. Technol. 19 (2008) 1643-1648.

[27] Y.W. Kim, J.T. Park, J.H. Koh, D.K. Roh, J.H. Kim, Anhydrous proton conducting membranes based on crosslinked graft copolymer electrolytes, J. Membr. Sci. 325 (2008) 319-325.

[28] J.H. Koh, J.A. Seo, J.T. Park, J.H. Kim, Synthesis and characterization of AgBr nanocomposites by templated amphiphilic comb polymer, J. Colloid Interface Sci. 338 (2009) 486-490.

[29] J.H. Koh, Y.W. Kim, J.T. Park, J.H. Kim, Templated synthesis of silver nanoparticles in amphiphilic poly (vinylidene fluoride-co-chlorotrifluoroethylene) comb copolymer, J. Polym. Sci. Part B: Polym. Phys. 46 (2008) 702-709.

[30] F. Liu, M.R.M. Abed, K. Li, Hydrophilic modification of P (VDF-Co-CTFE) porous membranes, Chem. Eng. Sci. 66 (2011) 27-35.

[31] D.K. Owens, R. Wendt, Estimation of the surface free energy of polymers, J. Appl. Polym. Sci. 13 (1969) 1741-1747.

[32] D. Hou, J. Wang, D. Qu, Z. Luan, X. Ren, Fabrication and characterization of hydrophobic PVDF hollow fiber membranes for desalination through direct contact membrane distillation, Sep. Purif. Technol. 69 (2009) 78-86.

[33] T.R. Dargaville, M. Celina, R. Clough, Evaluation of vinylidene fluoride poly- 
mers for use in space environments: comparison of radiation sensitivities, Radiat. Phys. Chem. 75 (2006) 432-442.

[34] A.M.W. Bulte, Nylon 4, 6 as membrane material: polymer crystallization during immersion precipitation, University of Twente, Enschede, 1994.

[35] L.P. Cheng, T.H. Young, W.Y. Chuang, L.Y. Chen, L.W. Chen, The formation mechanism of membranes prepared from the nonsolvent-solvent-crystalline polymer systems, Polymer 42 (2001) 443-451.
[36] L.P. Cheng, Effect of temperature on the formation of microporous PVDF membranes by precipitation from 1-octanol/DMF/PVDF and water/DMF/PVDF systems, Macromolecules 32 (1999) 6668-6674.

[37] M. Yeow, Y. Liu, K. Li, Isothermal phase diagrams and phase-inversion behavior of poly (vinylidene fluoride)/solvents/additives/water systems, J. Appl. Polym. Sci. 90 (2003) 2150-2155. 